\title{
Applications of FACTS/ESS in Power System Congestion Management with Large Renewable Energy Sources Using PSS/E and Experienced in National Grid of Pakistan
}

\author{
Zaira Anwar ${ }^{1}$, Tahir Nadeem Malik¹, Awais Sarfraz ${ }^{1}$, Hassan Hameed², Abdul Rehman², Tahir Abbas ${ }^{3}$ \\ ${ }^{1}$ Department of Electrical Engineering, University of Engineering \& Technology Taxila, Pakistan, ${ }^{2}$ Department of \\ Electrical Engineering, Islamia University of Bahawalpur, Pakistan, ${ }^{3}$ Department of Electrical Engineering, Lahore \\ University of Management Sciences, Lahore, Pakistan
}

\begin{abstract}
Network or transmission congestion is one of the technical challenges in context of power system operation. The congestion management have great impact in power system operations with the emerging technologies of large renewable sources. In Pakistan, the congestion issues are addressed in the area of National Grid of Pakistan. There are many techniques are proposed to relieve these issues. In this research paper, FACTS and ESS devices are proposed to curtail this issue in the PSS/E environment. It gives the reliable \& encouraging results and cost-effective solution.
\end{abstract}

Key words: Flexible AC transmission systems (FACTS); Energy storage systems (ESS); Power system simulator for engineers (PSS/E); Static volt-ampere reactive (VAR) compensator (SVC); Static compensator (STATCOM); Battery energy storage system (BESS)

Corresponding author's email: eshmal.fatima@yahoo.com

\section{INTRODUCTION}

In economically stressed situation of the world, the cost-effective methodology of the system is required. In this perspective of electrical industry, uninterruptable power supply to the consumers is today era need so, the new emerging techniques are developed which are economic as well as environment friendly. For this purpose, the renewable energy sources are introduced in the conventional networks such as wind and solar technologies. These emerging technologies played a superficial effect in the existing network according to need. In Pakistan, the environment is very feasible for these wind and solar energy technologies. The coastal area is used for the wind power generation and the desert is used for the solar power generation. Some mega projects of power generation are under construction using these technologies. Due to the old ones conventional networks, the congestion in the transmission lines is raised.

Network or transmission congestion (Nayak and Pai, 2002) is one of the technical challenges in context of power system operation. The transmission congestion occurs when there is insufficient transmission capacity to simultaneously accommodate all constraints. The constraints such as these limits of lines, voltage profile, thermal limits, overloading and generation integration reduces the quality of transmission.

\section{Causes of Congestion}

Congestion in the network is mainly due to the following reasons;

Limits of lines

Voltage Profile (Khanabadi et al., 2013)

Thermal Limits (Zafran et al., 2014)

Overloading (Pinheiro and Castro, 2015)

Demand Response (Li et al., 2015)

Generation Integration (Villumsen et al., 2013)

\section{Remedies of Congestion}

The literature review revealed that many methodologies are adopted to meet this challenge. Some methodologies such as re-dispatching of the generating units by back down or increase others units, curtailment of the load by achieving the willing-to-pay-to-avoid curtailment factor (Fang and David, 1999), genetic algorithm for optimal power flow (Ghahremani and Kamwa, 2014), dynamic thermal rating methodology by considering the actual conditions of line (Zafran et al., 2014), demand response model using 
IBDR and probabilistic model (Li et al., 2015), branch switching using sensitivity analysis (Pinheiro et al., 2015), N -1 contingency analysis using bender's decomposition (Khanabadi et al., 2013) N-1 -1 contingency analysis based on interdiction flow (Fan et al., 2012), two stage stochastic model based on decision in investment and operation of switching action (Villumsen et al., 2013) in the transmission network to alleviate the congestion in the system.

Table 1: Remedies of Congestion

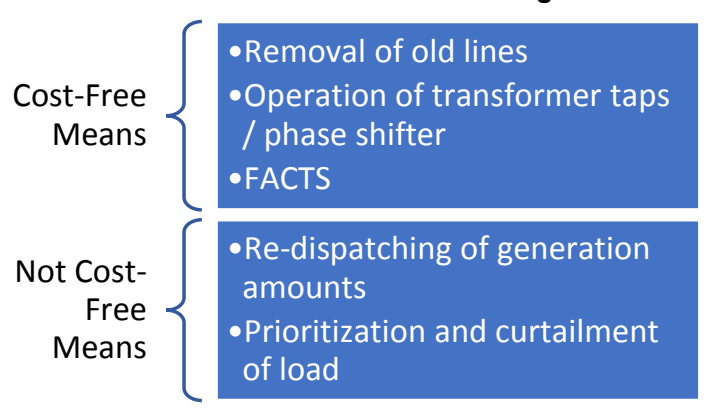

In this paper, we have focused on congestion management issue which has been addressed using Flexible AC Transmission System (FACTS) devices (Ghahremani and Kamwa, 2014; Mohanty et al., 2012). The integration of Energy storage system (ESS) devices (Smith et al., 2008) gives more promising results.

\section{System Model}

The existed and proposed network of National Grid of Pakistan is presented in this paper which is consisted of;

a) Primary Transmission Network

b) Secondary Transmission Network

c) Primary Distribution Network

d) Secondary Distribution Network

National Grid network is modeled in PSS/E environment by inserting all parameters of the lines, busses, generator, exciters, governors, transformers and loads. The single line diagram as well as save case files are generated in this tool. Then the steady state analysis using Newton Raphson Method is obtained which showed the congested locations in the network. One of the congested location such as QESCO is selected due to its poor stability in the network. It has disturbed voltage profile, frequency, load flows and rotor angle of generators.

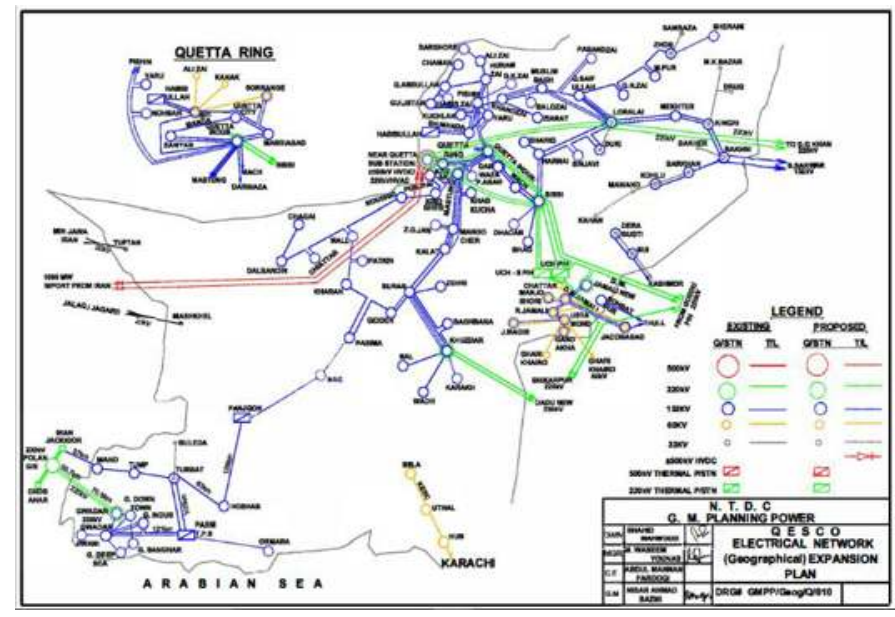

Figure 1: QESCO Network 
In QESCO network, the loading of the lines are shown in PSS/E tool which showed the highly loaded area of the network.

Transmission Expansion Plan for Gwadar Area

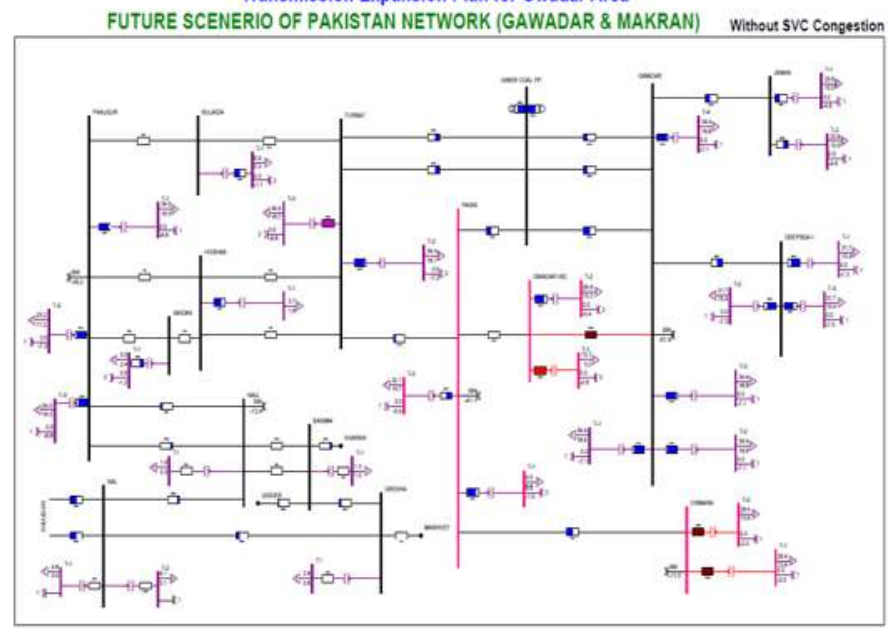

Figure 2: Loading of lines

In case of contingency, when the line is tripped due to fault or switching from Gwadar to Gwadar Coal then the lines are more heavily loaded, shown in red color, and does not maintain their stable state.

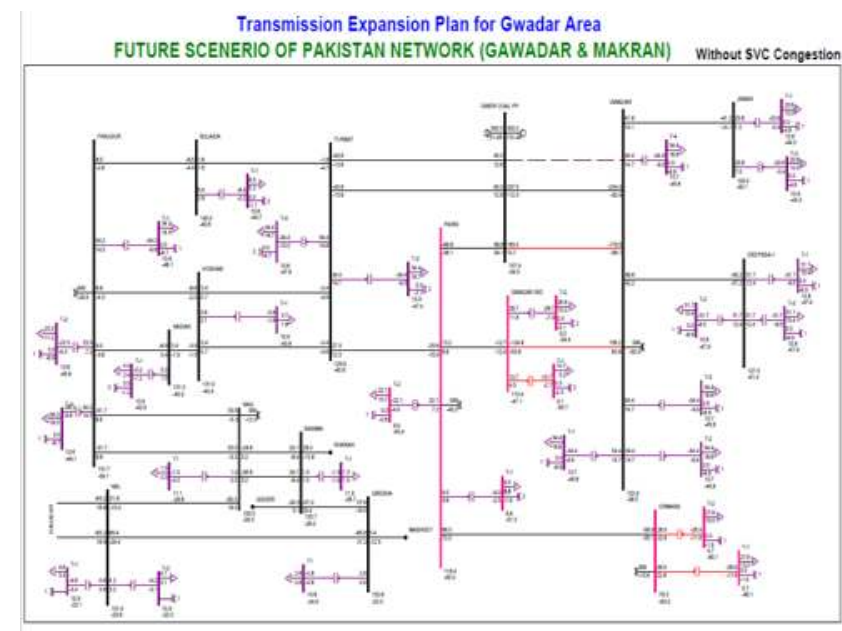

\section{Stability Studies}

Figure 3: Loading of lines in case of line tripping

The condition of being stable even after the disturbance in the network is the major need of the power system. The disturbance is basically due to the switching, faults and outage of the lines or equipment. These disturbances have a great impact of the voltage, frequency, and rotor angle profiles. Power system stability is mainly classified into rotor angle, frequency and voltage stability and further classified into short and long-term phenomenon.

\section{MATERIALS AND METHODS}

The system of being stable even after the disturbance. The following disturbances are studied;

- The severe three-phase balanced fault as per Grid Code of National Electric Power Regulatory Authority (NEPRA) is occurred on the bus bar at critical locations. It remains for the 5 cycles. 
- The three-phase fault will be backed up in 9 cycles after fault initiation.

- Contingency is applied for unbalancing of system and remain for 20 cycles.

In case of poor damping or oscillations in system recovery after the disturbance is cleared in the simulations. The remedy solutions are proposed to install the FACTS \& ESS devices and establish the proposed solutions through simulations.

\section{Voltage Waveform}

The graph of voltage waveform is plotted against the time axis. The range of time is 20 cycle whereas the range of voltage is $\pm 10 \%$ of its rated voltage. The voltage waveform of Gwadar, Pasni, Turbat and Gwadar Coal bus bars are shown in the figure. At the time of fault, voltages of the bus bars are suddenly drops and does not maintain the stable state even after the fault clearance.

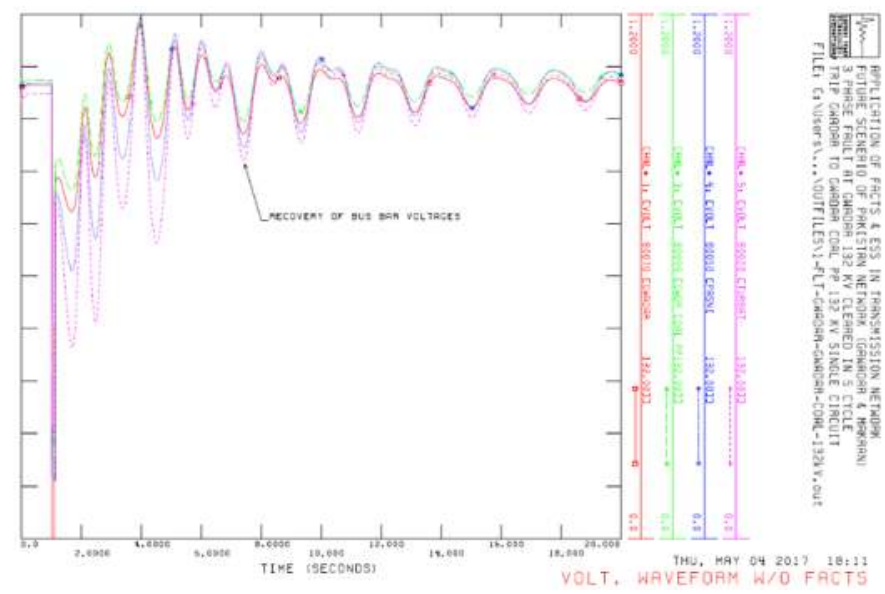

\section{Frequency Waveform}

Figure 4: Voltage waveform

The graph of frequency waveform is plotted against the frequency axis. The range of time is 20 cycle whereas the range of frequency is $\pm 1 \%$ of its rated frequency.

At the time of fault, the frequency of Gwadar bus bar has more excirsions in the system and exceed the rated boundary of the frequency. It does not approach the stable state in 20 cycles after the fault clearence.

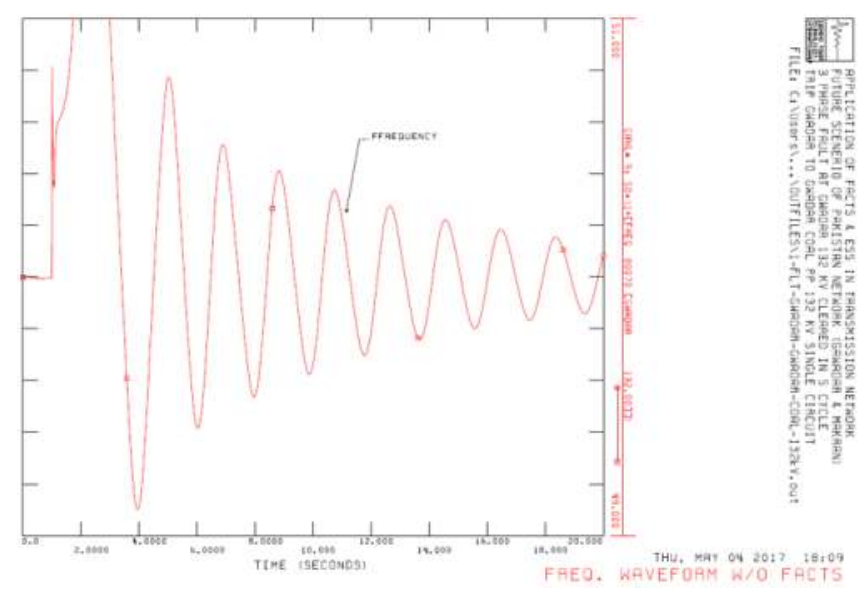

Figure 5: Frequency waveform

\section{Power Flow Waveform}

The graph of power flow waveform is plotted against the time axis. The one circuit of Gwadar to Gwadar 
Coal is switched thus the flow is carried out from the another circuit that is parallel to it. At the time of fault, the MW flow is drops out and its oscillation remains after the recovery of the system whereas the MVAR flow reaches its peak value and does not approach the stable state within the 20 cycles.

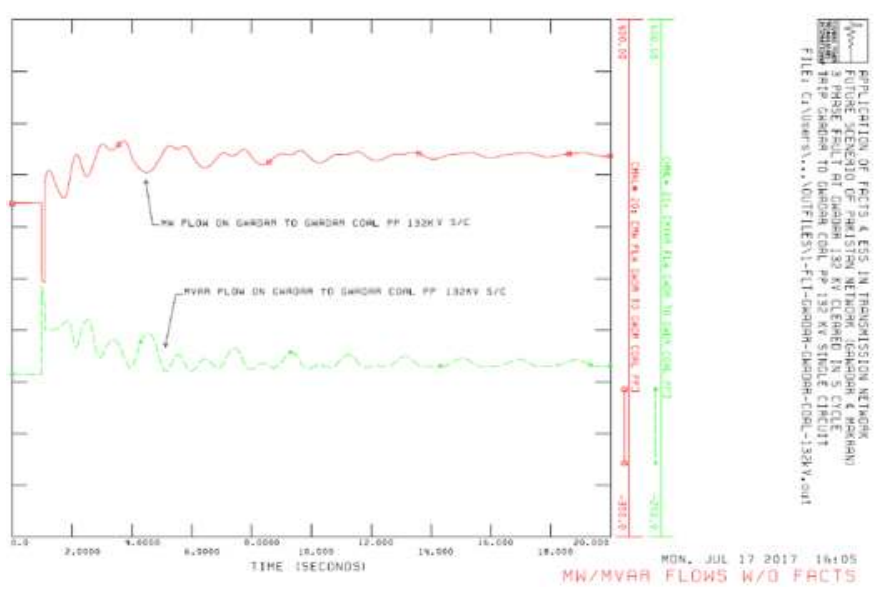

Figure 6: Power flow waveform

\section{Angle Waveform}

The graph of angle waveform is plotted against the time axis. The rotor angle of generator at Gwadar Coal is plotted relative to rotor angle of Tarbela generator. At the time of fault, rotor angle reaches its maximum peak It does not approach the stable state even after the fault clearence.

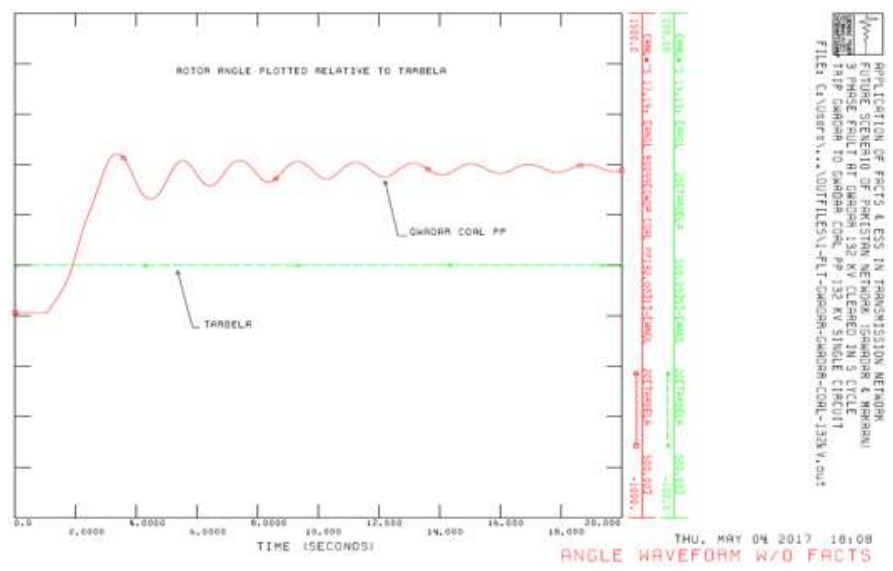

Figure 7: Angle waveform

\section{Implementation of Facts Devices}

Congestion includes MW loading and MVAR loading. The traditional solution to MW loading is the installation of a new circuit while the solution to MVAR loading is usually installation of capacitors. However, these are not feasible or reliable solutions due to either high cost (in case of stringing new circuits) or due to nonexistent support during fault conditions (in case adding capacitors).

In the selected critical region, Gwadar is located in a remote region as far as the electrical network is concerned. There is no local generation, so it needs to draw power from the National Grid, which passes hundreds of kilometers away from Gwadar. The long transmission lines needed to transport this power need to carry high amounts of reactive power, which causes significant MVAR loading in the network. Again, the traditional solution to this scenario is the addition of transmission lines. However, this is an expensive solution, 
especially since hundreds of kilometers worth of transmission towers, insulators and conductors are involved. So, SVC and STATCOM are proposed for providing MVARs in the system.

SVC

SVC is the shunt controller without any controlling switch. In this paper, CSVGN1 model of SVC is implemented. It provides the reactive power in case of inductive load and consumes reactive power in case of capacitive load. The SCR switch is controlled by the auxiliary signal. It controls the voltage and provide transient and dynamic stability.

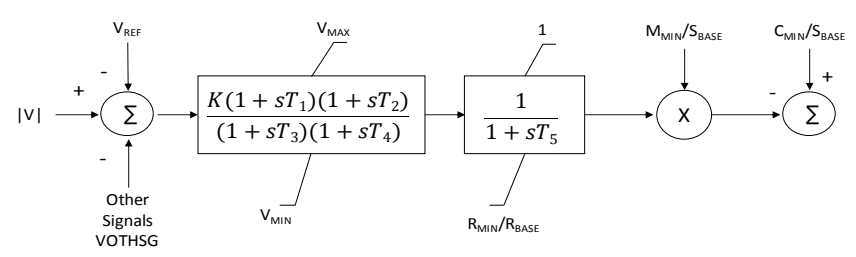

Figure 8: Control Diagram of SVC

The loading of the lines are relieved by installation of SVC which is shown in given figure.

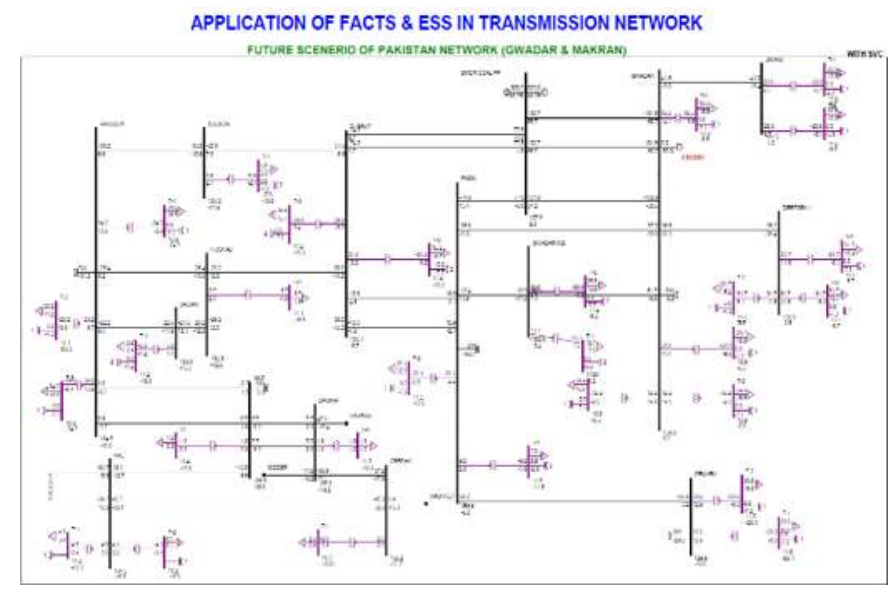

Figure 9: QESCO network with SVC

\section{Voltage Waveform with SVC}

The graph of voltage waveform is plotted against the time axis. The range of time is 20 cycle whereas the range of voltage is $\pm 10 \%$ of its rated voltage. The voltage waveforms of Gwadar, Pasni, Turbat and Gwadar Coal are drooped at the time of fault at Gwadar bus bar. With the installation of SVC, the voltages of the bus bars are recovered after the fault clearance within the 8 cycles.

\section{Frequency Waveform with SVC}

The graph of frequency waveform is plotted against the time axis. The range of time is 20 cycle whereas the range of frequency is $\pm 1 \%$ of its rated frequency. With the installation of SVC, The frequency reaches its peak value within its plot book, at the time of fault. The frequency of Gwadar bus bar drops at the time of fault. It is recovered after the 4 peaks within the 8 cycles.

\section{Power Flow Waveform with SVC}

The graph of power flow waveform is plotted against the time axis. The one circuit of Gwadar to Gwadar Coal is switched thus the flow is carried out from the another circuit that is parallel to it. At the time of fault, the MW flow is drops out and its oscillation remains for 6 cycles whereas the MVAR flow reaches its peak value and approached the stable state within the 8 cycles. 
Applications of FACTS/ESS in Power System Congestion Management with Large Renewable Energy Sources Using PSS/E and Experienced in National Grid of Pakistan

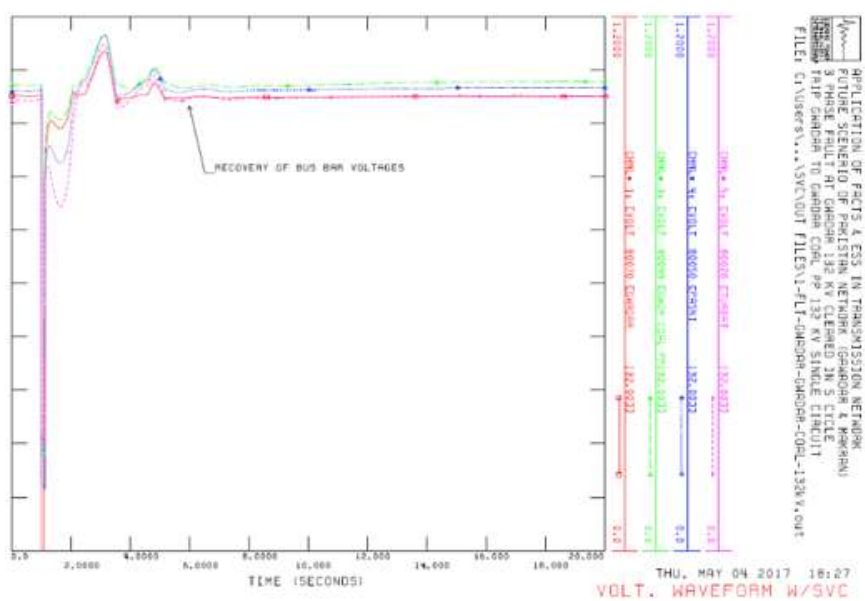

Figure 10: Voltage waveform with SVC

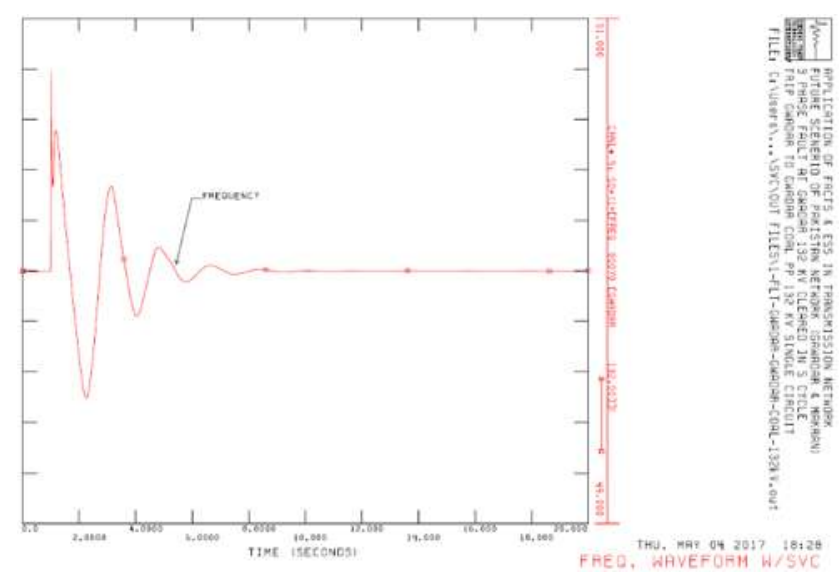

Figure 11: Frequency waveform with SVC

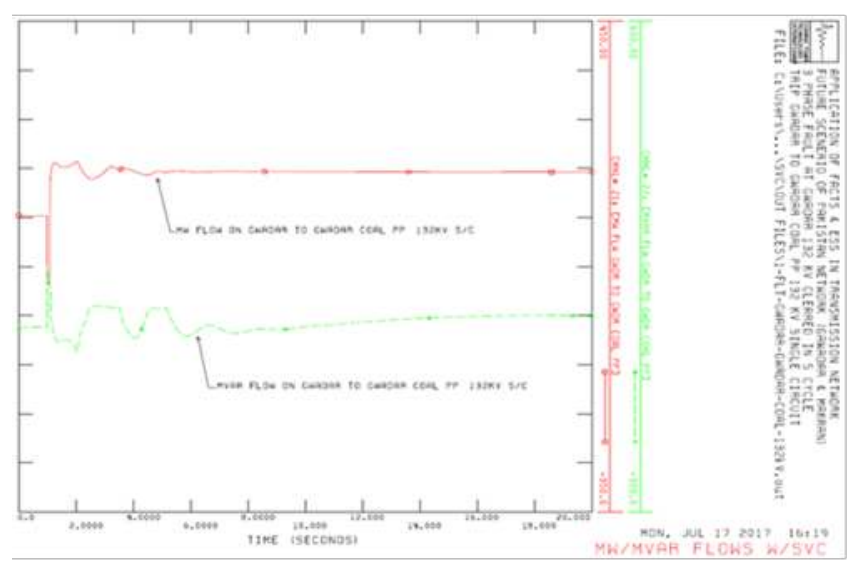

Figure 12: Power flow waveform with SVC 


\section{Angle Waveform with SVC}

The graph of angle waveform is plotted against the time axis The rotor angle of generator at Gwadar Coal is plotted relative to rotor angle of Tarbela generator. With the installation of SVC, rotor angle reaches its maximum peak and being stable within the 8 cycles after the fault clearence.

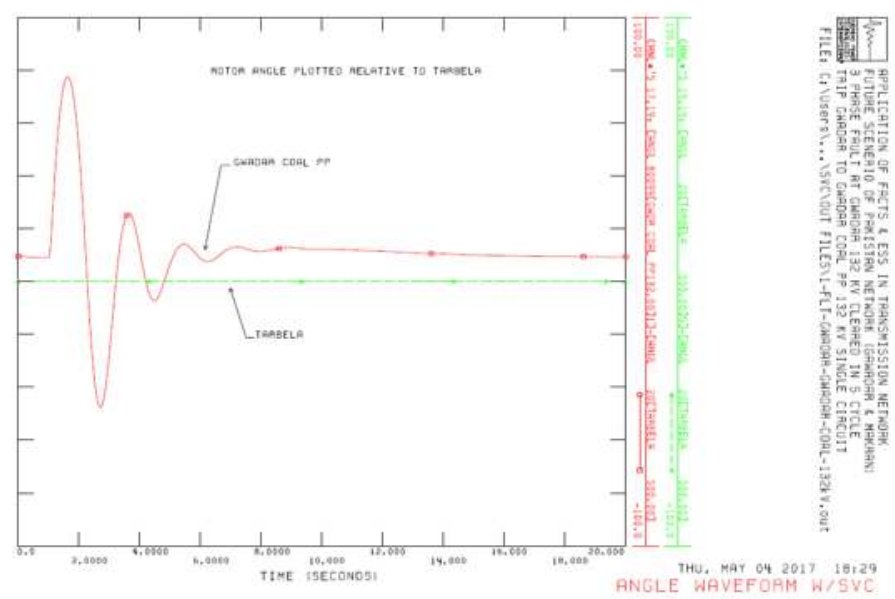

\section{SVC Output Wavefor}

Figure 13: Angle waveform with SVC

The graph of output current waveform is plotted against the time axis. SVC provides the current when the sytem stability drops due to fault occurrence. After the fault cleraence, SVC gives current untill the system achieved its stable state.

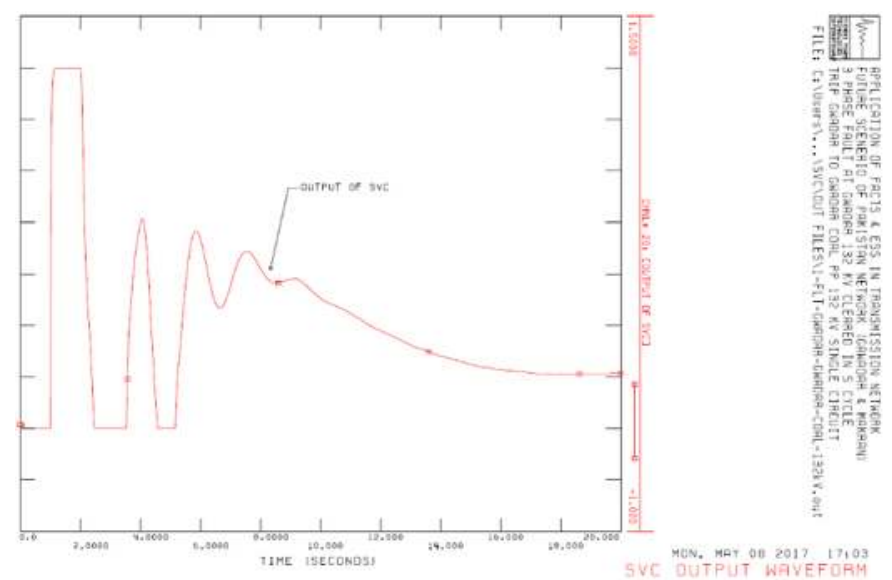

Figure 14: Output waveform of SVC

\section{Discussion on SVC}

The dynamic stability of the network is shown by the figures of voltage recovery, frequency and angle in which they are recovered within 8 cycles. The results with SVC are given below;

- Reactive power is provided according to the requirement of system.

- The capability of transmission lines is increased up to $60 \%$ on 300 MVAR.

- Dynamic stability of the system is enhanced.

- Low cost solution is obtained.

It is also observed that more switching time is needed to give VARs in the system. The results can be improved with the fast switching device, thus STATCOM is proposed. 


\section{STATCOM}

Static condenser (STATCON) or static compensator (STATCOM) is a shunt capacitor that is voltage source convertor with thyristor-controlled switch. It is used to control the reactive power that has direct relation with the voltage. The voltage is synthesized behind the convertor transformer reactance. For the reactive control, the synthesized voltage is kept in phase with the terminal voltage. In ideal condition, the capacitor remains charged because there is no exchange of active power with the network. In practical network, the convertor has losses and a trend of discharging of capacitor is followed. For charging of capacitor, the voltage is controlled and lag by the terminal voltage, thus the active power flow between the system and condenser is maintained. In this way, the voltage of the capacitor is controlled which determine the internal voltage that control the reactive power exchange with the network.

In this paper, CSTATT and CSTCNT models of STATCON are modeled in which only the reactive power is presented whereas the active power is considered as negligible. Both types of STATCON have same dynamic models with no active output power. The main difference is that, CSTATT is modeled as synchronous condenser while CSTCNT is modeled as FACTS device.

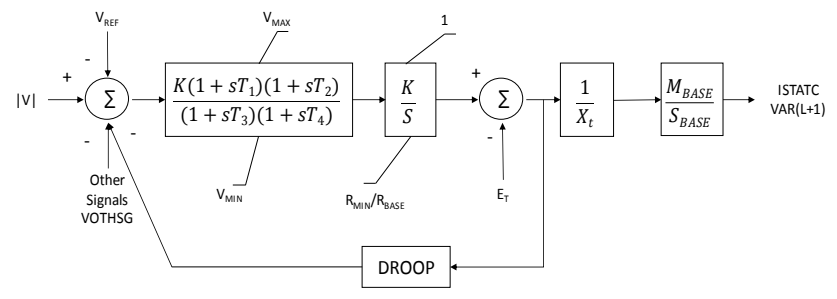

Figure 15: Control Diagram of STATCOM (CSTATT)

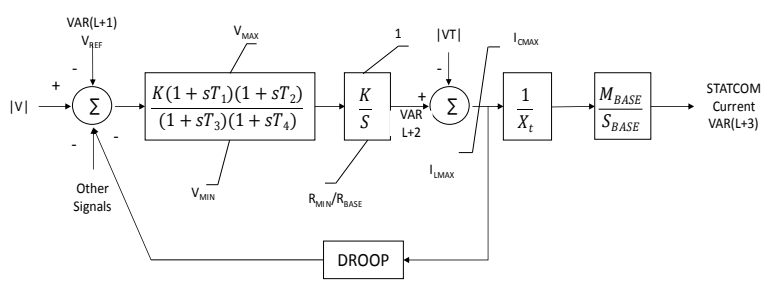

Figure 16: Control Diagram of STATCOM (CSTCNT)

STATCOM (CSTATT)

The loading of the lines are relieved by installation of CSTATT which is shown in given figure.

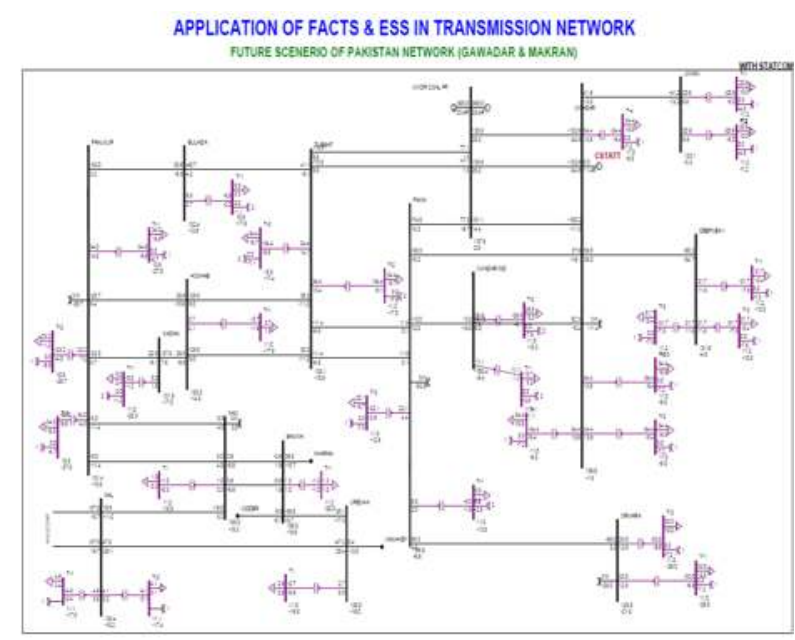

Figure 17: QESCO Network with STATCOM(CSTATT) 


\section{Voltage Waveform with CSTATT}

The graph of voltage waveform is plotted against the time axis. The range of time is 20 cycle whereas the range of voltage is $\pm 10 \%$ of its rated voltage. The voltage waveforms of Gwadar, Pasni, Turbat and Gwadar Coal are drooped at the time of fault at Gwadar bus bar. With the installation of CSTATT, the voltages of the bus bars are recovered after the fault clearance within the 7 cycles.

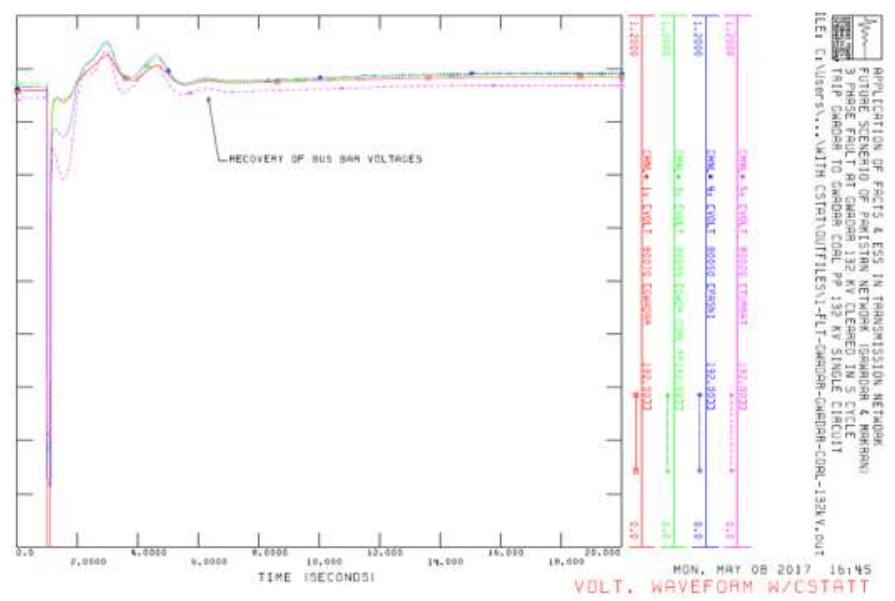

Figure 18: Voltage waveform with STATCOM (CSTATT)

\section{Frequency Waveform with CSTATT}

The graph of frequency waveform is plotted against the time axis. The range of time is 20 cycle whereas the range of frequency is $\pm 1 \%$ of its rated frequency. With the installation of CSTATT, the frequency of Gwadar bus bar reaches its maximum value but within its range of plot area at the time of fault. After the fault clearence, it drops and after some oscillations it maintained the stable state within the 7.5 cycles.

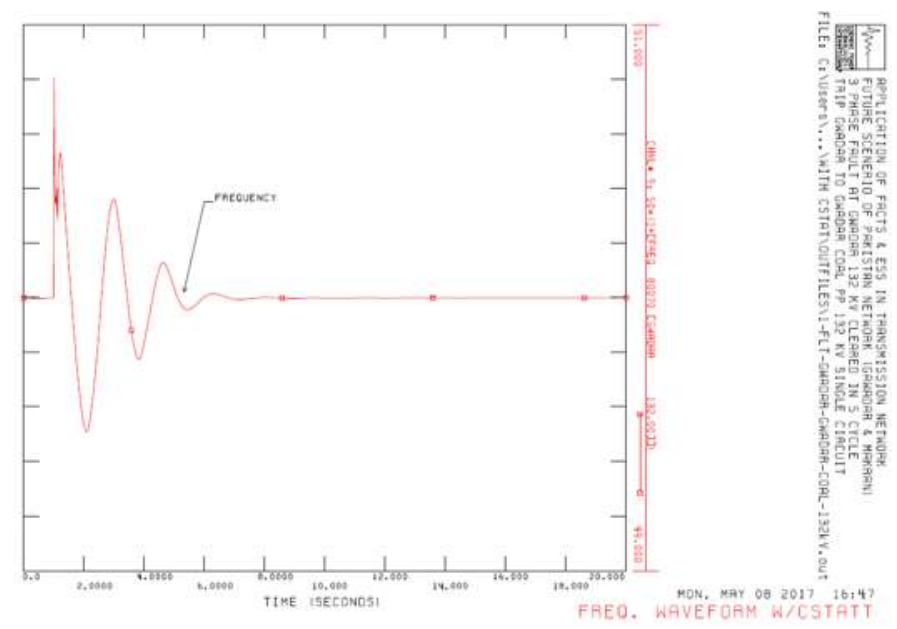

Figure 19: Frequency waveform with STATCOM (CSTATT)

\section{Power Flow Waveform with CSTATT}

The graph of power flow waveform is plotted against the time axis. The one circuit of Gwadar to Gwadar Coal is switched thus the flow is carried out from the another circuit that is parallel to it. At the time of fault, the MW flow is drops out and its oscillation remains for 6 cycles whereas the MVAR flow reaches its peak value and approached the stable state within the 7 cycles. 


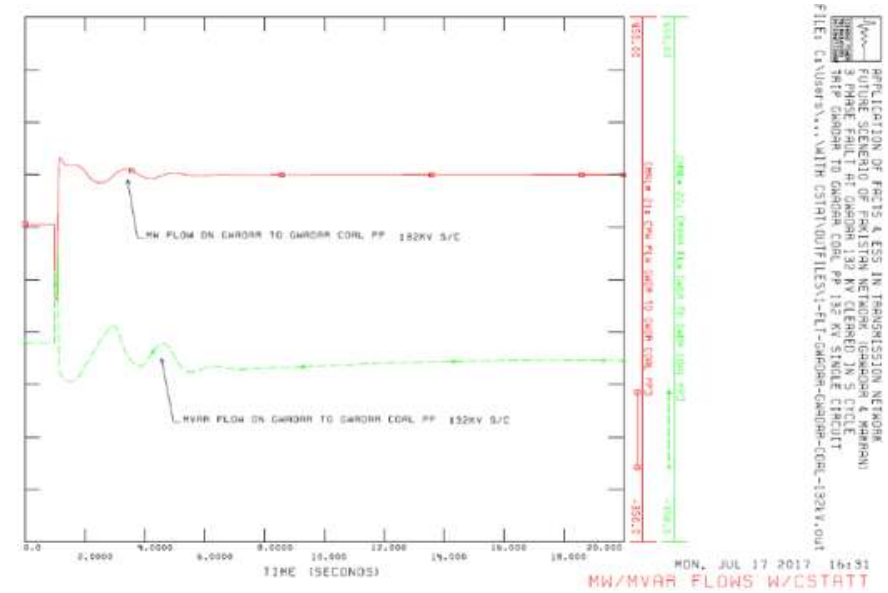

Figure 20: Power Flow waveform with STATCOM (CSTATT)

\section{Angle Waveform with CSTATT}

The graph of angle waveform is plotted between against the time axis. The rotor angle of generator at Gwadar Coal is plotted relative to rotor angle of Tarbela generator. With the installation of CSTATT, the first swing has value within the boundry of plot area. After the fault clearence, the system attained the stable state within the 7.5 cycles.

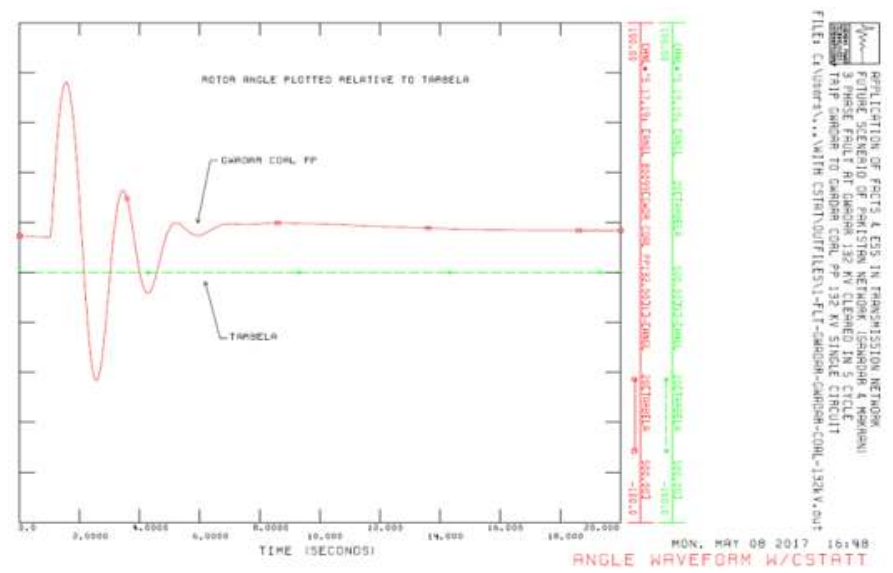

Figure 21: Angle waveform with STATCOM (CSTATT)

\section{CSTATT Output Waveform}

The graph of output current waveform is plotted against the time axis. CSTATT provides the current when the sytem stability drops due to fault occurrence. After the fault cleraence, SVC gives current untill the system achieved its stable state.

\section{STATCOM (CSTCNT)}

The loading of the lines are relieved by installation of CSTCNT which is shown in given figure.

\section{Voltage Waveform with CSTCNT}

The graph of voltage waveform is plotted against the time axis. The range of time is 20 cycle whereas the range of voltage is $\pm 10 \%$ of its rated voltage.

The voltage waveforms of Gwadar, Pasni, Turbat and Gwadar Coal are drooped at the time of fault at Gwadar bus bar. With the installation of CSTCNT, the voltages of the bus bars are recovered after the fault clearance within the 6.5 cycles. 
Applications of FACTS/ESS in Power System Congestion Management with Large Renewable Energy Sources Using PSS/E and Experienced in National Grid of Pakistan

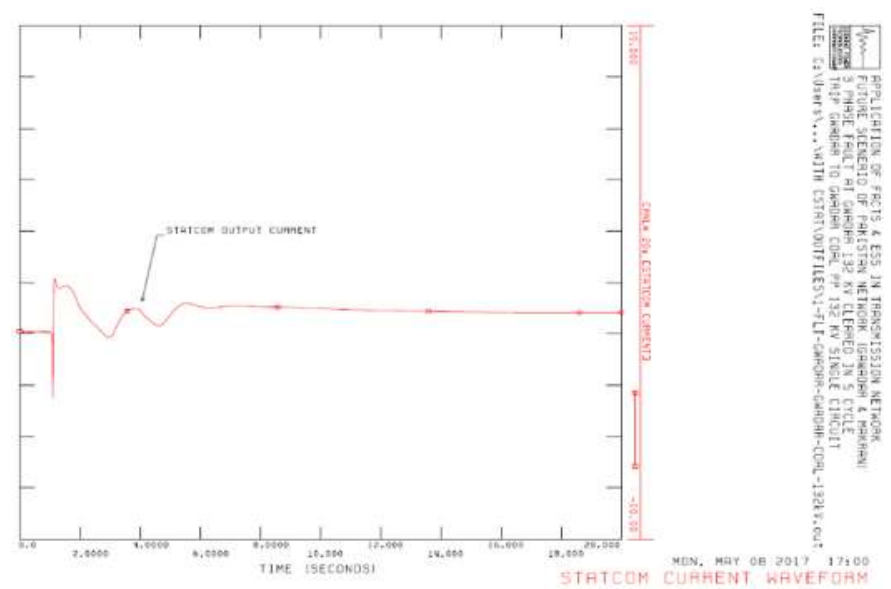

Figure 22: Output waveform of STATCOM (CSTATT)

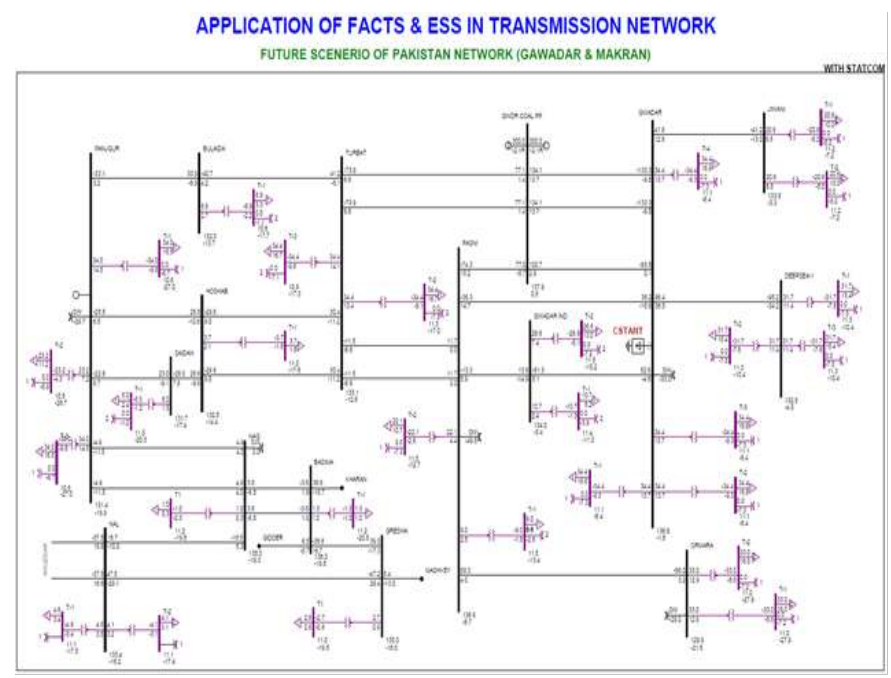

Figure 23: QESCO Network with STATCOM(CSTCNT)

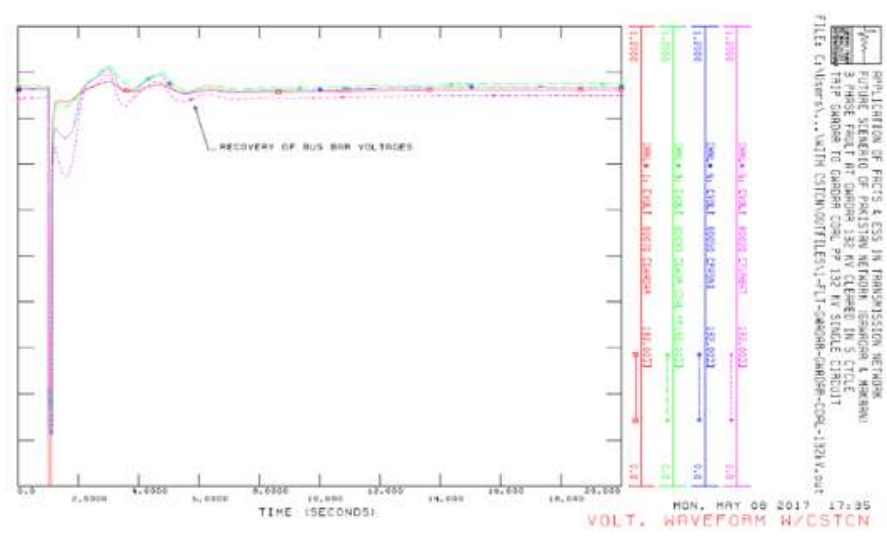

Figure 24: Voltage waveform with STATCOM (CSTCNT) 


\section{Frequency Waveform with CSTCNT}

The graph of frequency waveform is plotted against the time axis. The range of time is 20 cycle whereas the range of frequency is $\pm 1 \%$ of its rated frequency.

With the installation of CSTCNT, the frequency of Gwadar bus bar reaches its maximum value but within its range of plot area at the time of fault. After the fault clearence, it drops and after some oscillations it maintained the stable state within the 7 cycles.
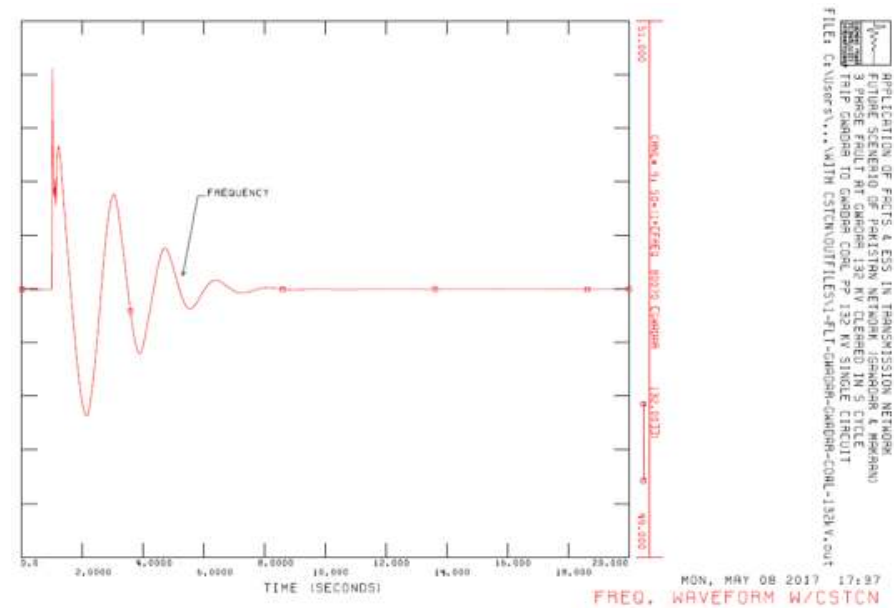

Figure 25: Frequency waveform with STATCOM (CSTCNT)

\section{Power Flow Waveform with CSTCNT}

The graph of power flow waveform is plotted against the time axis. The one circuit of Gwadar to Gwadar Coal is switched thus the flow is carried out from the another circuit that is parallel to it. At the time of fault, the MW flow is drops out and its oscillation remains for 6 cycles whereas the MVAR flow reaches its peak value and approached the stable state within the 8 cycles.

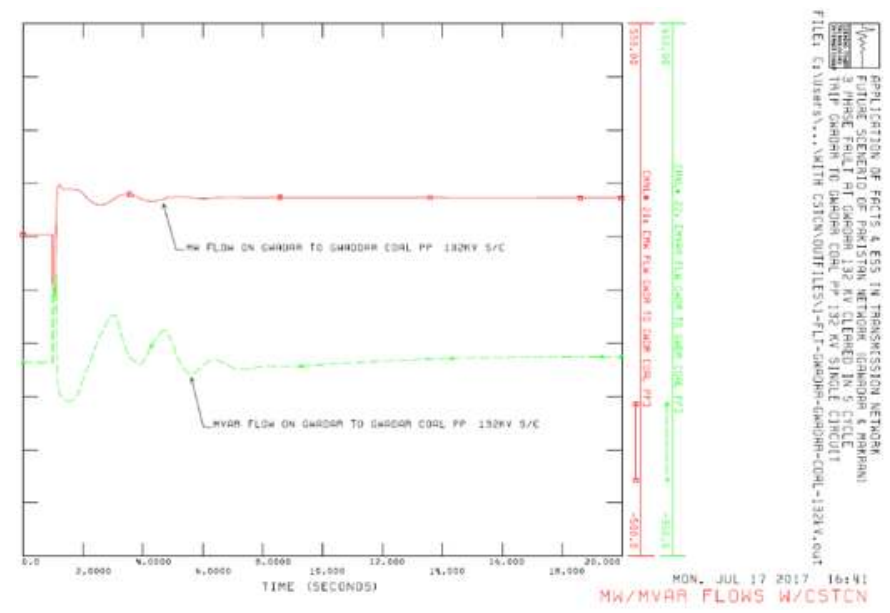

Figure 26: Power Flow waveform with STATCOM (CSTCNT)

\section{Angle Waveform with CSTCNT}

The graph of angle waveform is plotted against the time axis The rotor angle of generator at Gwadar Coal is plotted relative to rotor angle of Tarbela generator. With the installation of CSTCNT, the first swing has value within the boundry of plot area. After the fault clearence, the system attained the stable state within the 11 cycles. 
Applications of FACTS/ESS in Power System Congestion Management with Large Renewable Energy Sources Using PSS/E and Experienced in National Grid of Pakistan

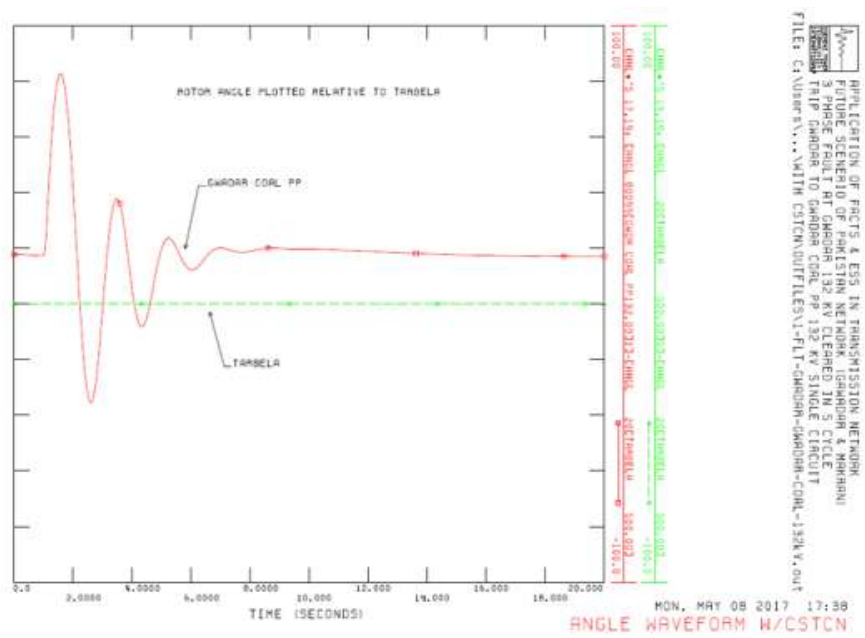

Figure 27: Angle waveform with STATCOM (CSTCNT)

\section{CSTCNT Output current waveform}

The graph of output current waveform is plotted against the time axis. CSTCNT provides the current when the sytem stability drops due to fault occurrence. After the fault cleraence, SVC gives current untill the system achieved its stable state.

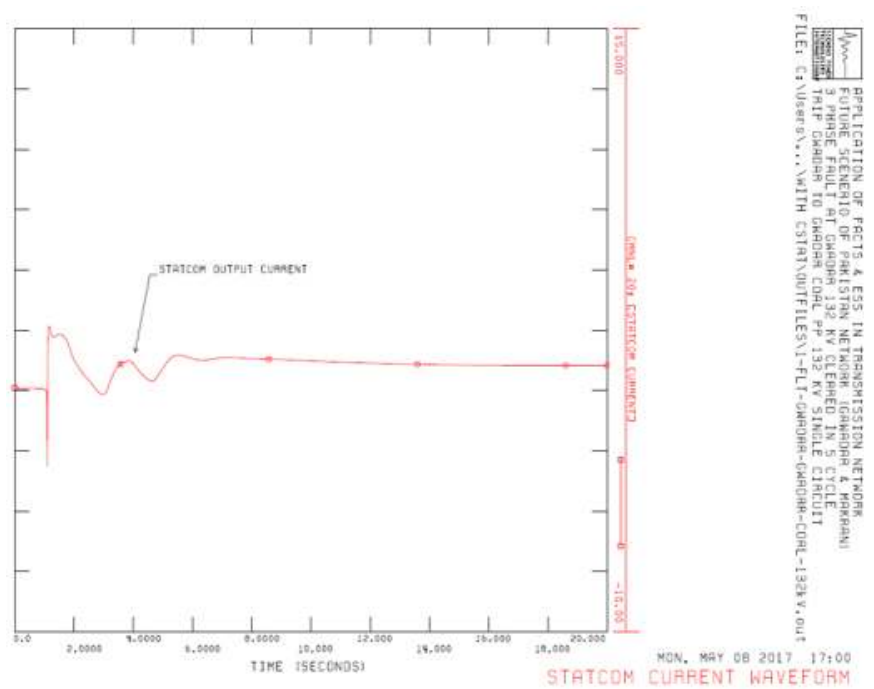

\section{Discussion on STATCOM}

Figure 28: Output waveform of STATCOM (CSTCNT)

The dynamic stability of the network is shown by the figures of voltage recovery, frequency and angle in which they are recovered within 7 cycles. The results with STATCOM are given below;

- Reactive power is provided according to the requirement of system.

- The capability of transmission lines is increased up to $65 \%$ on 150 MVAR.

- Dynamic stability of the system is enhanced.

- High Losses

- High cost solution is obtained. 
It is also observed that issue of power factor and transients are introduced in the system. The results could be improved by the integration of ESS device such as BESS, thus BESS is proposed.

\section{Implementation of ESS Devices}

\section{BESS}

CBEST is the model of battery energy storage system that is used to improve the first swing and limit the frequency excursions. In this paper, it is used with STATCOM for the better results of the network. The input and output power of the CBEST is controlled by the terminal voltage. The convertor provides independence between dc voltage and synthesized voltage behind convertor reactance. In this way, it allows the independent control of active and reactive control.

The active power path of CBEST model simulates the power limitations and current limitations of convertor. The rating of the CBEST is taken according to the energy demand that covers the energy demand during simulations.

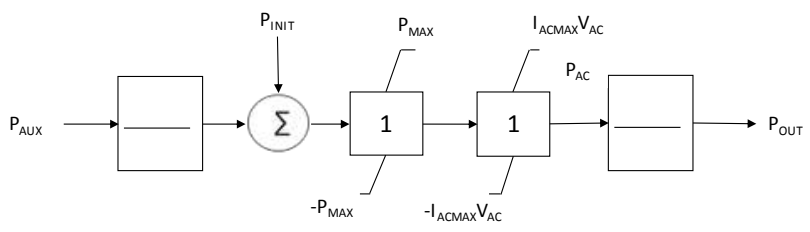

Figure 29: Control Diagram of BESS

The loading of the lines are relieved by integrating the BESS with STATCOM which is shown in given figure.

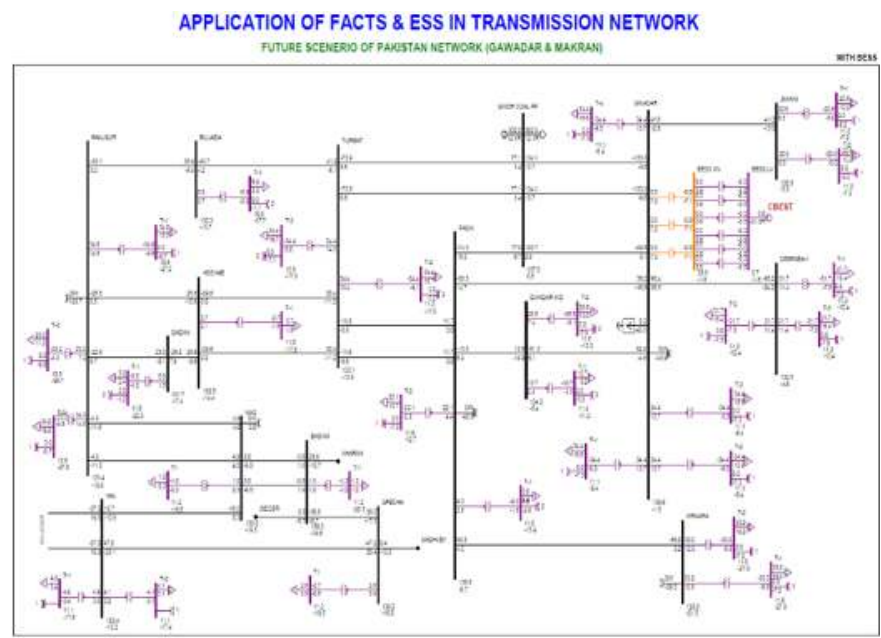

Figure 30: QESCO Network with STATCOM and BESS

\section{Voltage Waveform with BESS}

The graph of voltage waveform is plotted against the time axis. The range of time is 20 cycle whereas the range of voltage is $\pm 10 \%$ of its rated voltage. The voltage waveforms of Gwadar, Pasni, Turbat and Gwadar Coal are drooped at the time of fault at Gwadar bus bar. With the installation of BESS, the voltages of the bus bars are recovered after the fault clearance within the 6 cycles.

\section{Frequency Waveform with BESS}

The graph of frequency waveform is plotted against the time axis. The range of time is 20 cycle whereas the range of frequency is $\pm 1 \%$ of its rated frequency. With the installation of SVC, the frequency of Gwadar bus bar reaches its maximum value but within its range of plot area the time of fault. After the fault clearence, it drops and after some oscillations it maintained the stable state within the 7 cycles. 


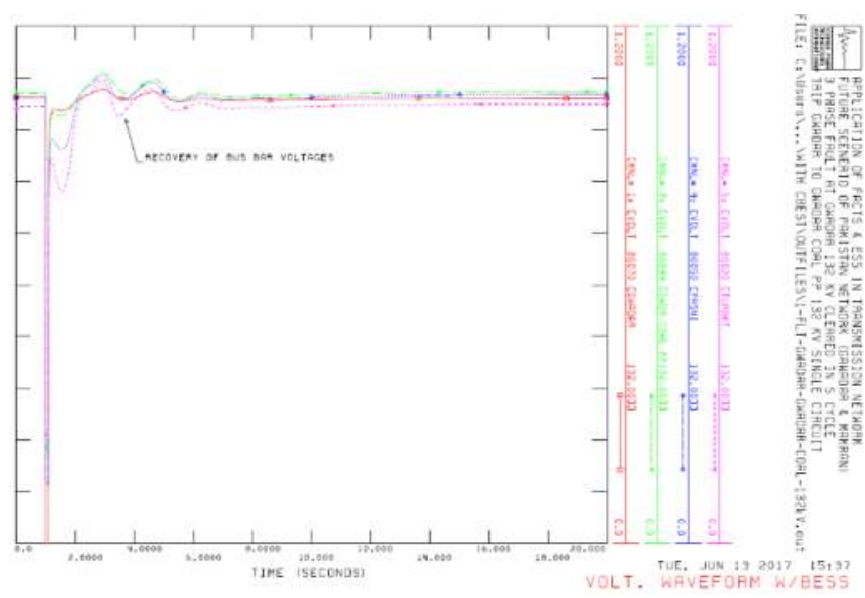

Figure 31: Voltage waveform with STATCOM \& BESS

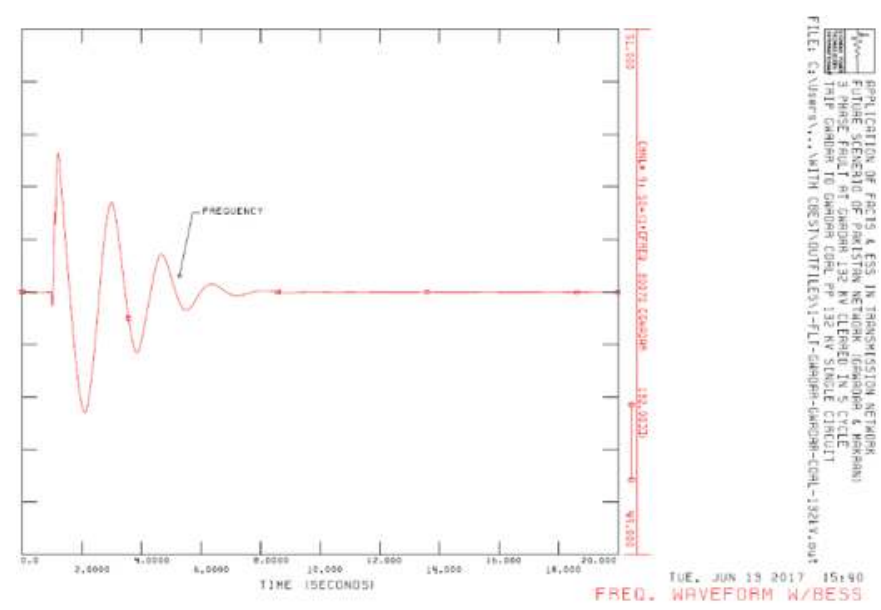

Figure 32: Frequency waveform with STATCOM \& BESS

\section{Power Flow Waveform with BESS}

The graph of power flow waveform is plotted against the time axis. The one circuit of Gwadar to Gwadar Coal is switched thus the flow is carried out from the another circuit that is parallel to it. At the time of fault, the MW flow is drops out and its oscillation remains for 5 cycles whereas the MVAR flow reaches its peak value and approached the stable state within the 6 cycles.

\section{Angle Waveform with BESS}

The graph of angle waveform is plotted against the time axis. The rotor angle of generator at Gwadar Coal is plotted relative to rotor angle of Tarbela generator. With the installation of BESS, the first swing has value within the boundry of plot area. After the fault clearence, the system attained the stable state within the 6 cycles.

\section{BESS Output Current Waveform}

The graph of output current waveform is plotted against the time axis. BESS provides the current when the sytem stability drops due to fault occurrence. After the fault cleraence, BESS gives current untill the system achieved its stable state. 
Applications of FACTS/ESS in Power System Congestion Management with Large Renewable Energy Sources Using PSS/E and Experienced in National Grid of Pakistan

BESS Output MW waveform

The garph of Output MW is plotted against the time axis. BESS provides the MW when the sytem stability drops due to fault occurrence. After the fault cleraence, BESS gives MW untill the system achieved its stable state.

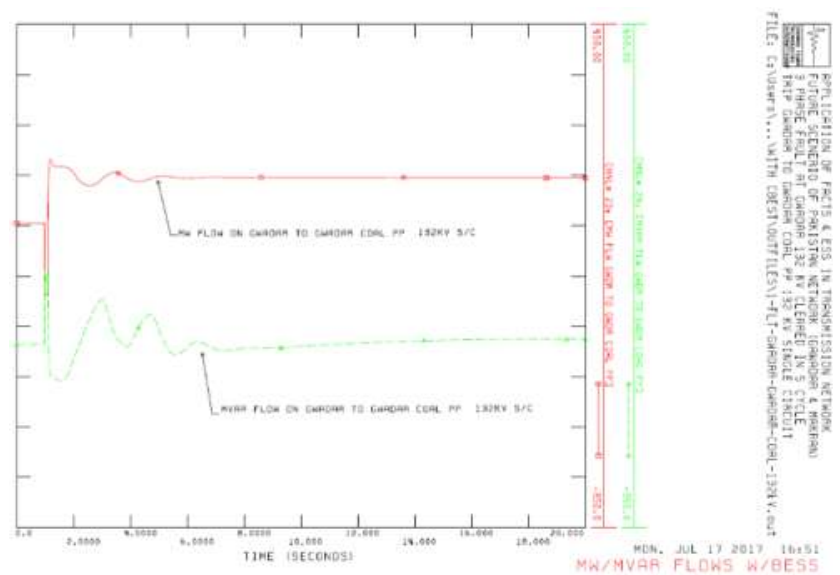

Figure 33: Power Flow waveform with STATCOM \& BESS

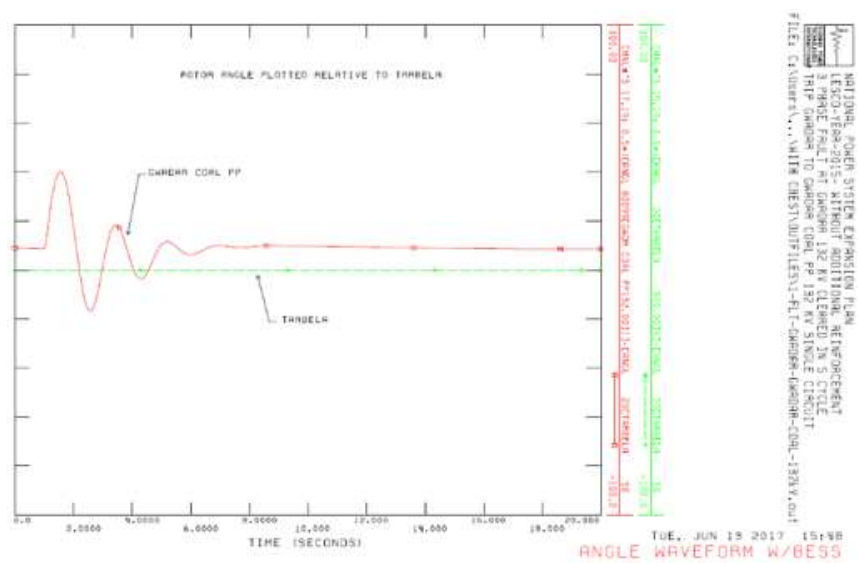

Figure 34: Angle waveform with STATCOM \& BESS

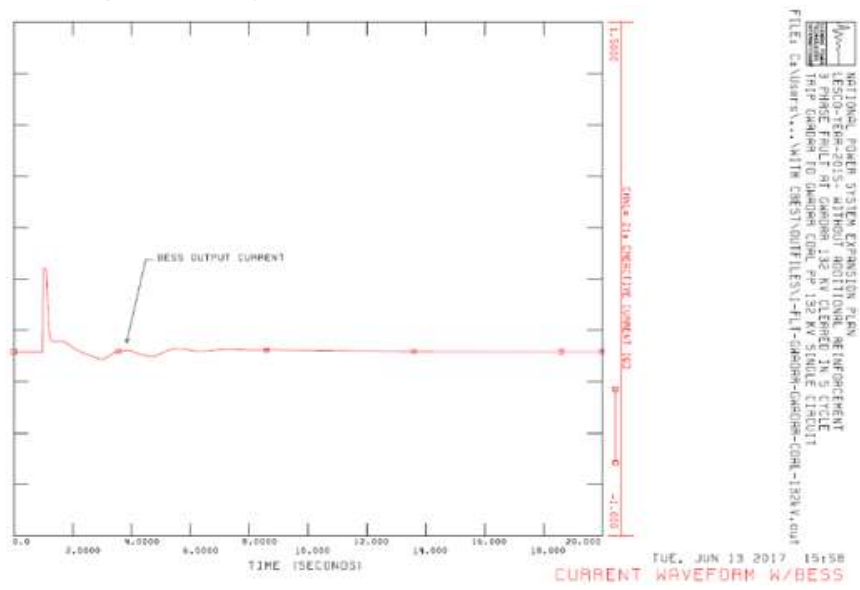

Figure 35: Output waveform of STATCOM \& BESS 


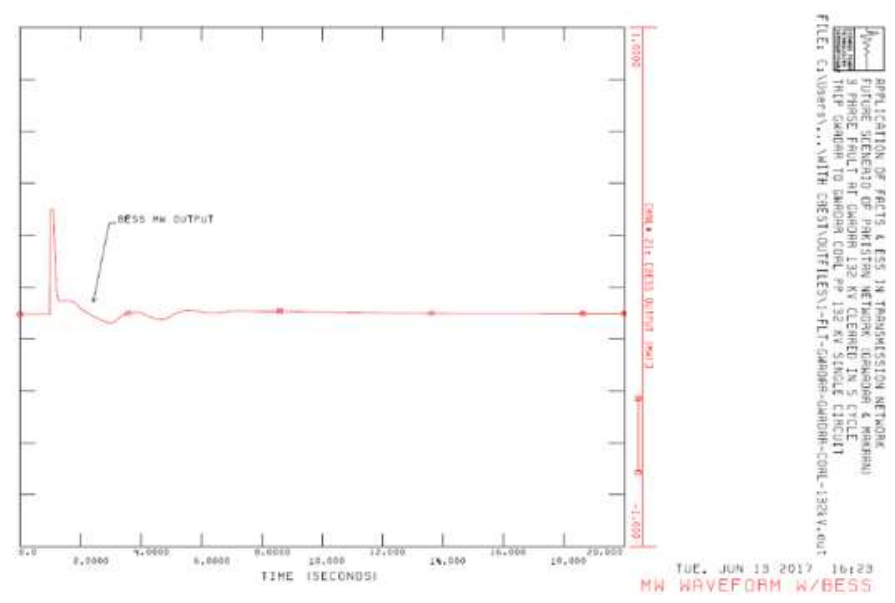

Figure 36: Output waveform of STATCOM \& BESS

\section{Discussion on BESS}

The dynamic stability of the network is shown by the figures of voltage recovery, frequency and angle in which they are recovered within 6 cycles. The results with BESS are given below;

- Active and reactive power is provided according to the requirement of system.

- The capability of transmission lines is increased up to $70 \%$ on 150 MVAR and $150 \mathrm{MW}$.

- Dynamic and transient stability of the system is enhanced.

\section{RESULTS AND DISCUSSION}

Transmission line congestion has the critical impact on the power system stability. These stability issues are critically observed in QESCO network of Pakistan National Grid. The network is simulated in PSS/E tool that showed the highly unstable and overloaded network. In this paper, as a remedial solution, we have implemented the FACTS (SVC and STATCOM) devices. In this way, these devices only provides the reactive power in the network. So, we have integrated the ESS (BESS) with FACTS devices. In this way, it gives the reactive as well as active powers in the system according to requirements of the network. These devices provides the dynamic and transient stabilities in perspectives of voltage, frequency and rotor angles. In this way, it increases the transmission line capacity, frequency and power factor. It also provides the cost effective solution as compared to laid a new transmission line in the network. When a new transmission line is laid, it includes the material cost (tower, conductor, insulator strings, overhead line and spacers), installation cost (tower, conductor, insulator strings, overhead line and spacers), right of way cost, line bay cost, civil works cost and engineering cost for constructing the lines. These costs are much larger than the cost of FACTS \& ESS devices. That's why we preferred these devices for relieving the issue of congestion.

\section{CONCLUSIONS}

The transmission network is like the arteries that transfers power from the generating stations to load centers. While transmitting the power, the issue of congestion is raised due to generation integration and demand response in the transmission lines. There are many methodologies are adopted to relieve this issue. In this paper, our mainly focused on the FACTS \& ESS devices for mitigating this congestion issue.

As a first step, we implemented the SVC of 300 MVAR on the congested location of Pakistan National Grid. It enhances the transmission line capability but has low switching time for providing the VARs in the system. The switching time of the device is enhanced by the IGBTs switches. So, STATCOM of 150 MVAR is introduced in the system which provided the better dynamic stability and better switching for VARs controlling. In this way, the transients in the system are not being stabled thus BESS is integrated with STATCOM to give MWs in the system. It increases the frequency and power factor of the network. 


\section{REFERENCES}

- Khanabadi M, Ghasemi H, Doostizadeh M. (2013). Optimal transmission switching considering voltage security and N-1 contingency analysis. IEEE Transactions on Power Systems 28(1): 542-550.

- Zafran M, Arbab MN, Ahmad I, Khan MUK. (2014). A case study on alleviating electric transmission congestion using dynamic thermal rating methodology. 2014 International Conference on Energy Systems and Policies (ICESP), Islamabad. pp. 1-6.

- Pinheiro DC, Castro CA. (2015). Elimination of transmission system overloads through branch switching, 2015 IEEE Eindhoven Power Tech, Eindhoven. pp. 1-6.

- Nayak AS, Pai MA. (2002). Congestion Management in Restructured Power Systems Using an Optimal Power Flow Framework. PSERC Publications. Pp.1-47.

- Li C, Dong ZY, Chen G, Luo F, Liu J. (2015). Flexible transmission expansion planning associated with large scale wind farms integration considering demand response. IET Generation, Transmission \& Distribution 9(15):2276-2283.

- Villumsen JC, Bronmo G, Philpott AB. (2013). Line capacity expansion and transmission switching in power sytems with large scale wind power. in IEEE Transactions on Power Systems 28(2):731-739.

- Fang RS, David AK. (1999). Transmission congestion management in an electricity market. IEEE Transactions on Power Systems 14(3):877-883.

- Fan N, Chen R, Watson J. (2012). N - 1 - 1 contingency-constrained optimal power flow by interdiction method. IEEE Power and Energy Society General Meeting, San Diego, CA. pp. 1-6.

- Ghahremani E, Kamwa I. (2014). Analyzing the effects of different types of FACTS devices on the steady-state performance of the Hydro-Quebec network. IET Generation, Transmission \& Distribution 8(2): $233-249$.

- Mohanty AK, Barik AK. (2011). Power system stability improvement using FACTS devices. International Journal of Modern Engineering Research (IJMER) 1(2):666-672.

- Smith SC, Sen PK, Kroposki B. (2008). Advancement of energy storage devices and applications in electrical power system. 2008 IEEE Power and Energy Society General Meeting - Conversion and Delivery of Electrical Energy in the 21st Century, Pittsburgh, PA. pp. 1-8. 